\section{Análisis de los criterios para definir áreas de integración urbana en Chile}

\author{
Ignacio Tiznado-Aitken \\ ORCID: https://orcid.org/0000-0002-7385-2357 \\ Department of Human Geography, University of Toronto, \\ Toronto, Canadá. Centro de Desarrollo Urbano Sustentable \\ (CEDEUS), Santiago, Chile. \\ Correo electrónico: i.tiznadoaitken@utoronto.ca
}

\section{Clemente Larraín Videla}

ORCID: https://orcid.org/0000-0002-5775-8061

Centro de Estudios Públicos (CEP), Chile.

\begin{abstract}
Resumen
En Chile, distintos actores gubernamentales y públicos han propuesto una serie de condiciones que deben cumplir aquellas áreas donde se podrán aplicar incentivos normativos para proyectos de vivienda con integración social. En este trabajo, basados en el estado del arte de la geografía de transporte y accesibilidad, analizamos críticamente aquellos principios propuestos. A partir de la simulación de estos criterios en Santiago de Chile, utilizando datos abiertos y herramientas SIG, evaluamos si estos son suficientes para asegurar una adecuada accesibilidad al transporte público y al equipamiento urbano, además de cumplir con una capacidad de carga apropiada para la densificación. Los resultados indican que los criterios analizados consideran la accesibilidad al transporte público y a las oportunidades urbanas como dimensiones excluyentes y solo desde la perspectiva de proximidad territorial o distancia caminable. Por otra parte, los estándares propuestos no consideran adecuadamente la capacidad de carga, al tomar en cuenta solo áreas de influencia y obviar la capacidad de la infraestructura del transporte público. A partir de esto, realizamos propuestas y lineamientos que debieran incluirse al momento de definir áreas para la densificación con cuotas de vivienda social.
\end{abstract}

Palabras clave

Accesibilidad, Chile, integración social, territorio, transporte público

\section{Analysis of the criteria for defining urban integration areas in Chile}

\begin{abstract}
In Chile, different government and public actors have proposed several conditions that urban areas must fulfill to be destination of regulatory incentives for socially integrated housing projects. In this work, based on the state of the art of transport geography and accessibility, we critically analyze those proposed principles. Based on the simulation of these criteria in Santiago de Chile using open data and GIS tools, we evaluate whether these inputs are enough to ensure adequate accessibility to public transport and urban opportunities, in addition to satisfy an adequate load capacity for densification. The results show that the criteria analyzed consider accessibility to public transport and urban opportunities as exclusive dimensions and only from the territorial proximity or walking distance perspective. Moreover, the proposed standards do not adequately contemplate load capacity, considering only areas of influence and ignoring the public transport capacity. Based on this analysis, we make proposals and suggest guidelines that should be considered when defining areas for densification with social housing quotas.
\end{abstract}

\section{Keywords}

Accessibility, Chile, public transport, social integration, territory 


\section{Introducción}

La accesibilidad a oportunidades ha tomado protagonismo en la academia y en las políticas públicas como el objetivo central de una planificación de transporte que busque la justicia como fin último (Martens, 2017; Pereira et al., 2017). Para que este acceso sea equitativo, debe responder a las diferencias y necesidades de distintos grupos de población, otorgando las condiciones para que alcancen oportunidades que permitan su desarrollo social y económico (Lucas, 2012). Dentro de este contexto, promover iniciativas que faciliten la integración de los grupos más vulnerables de la sociedad, con buenas condiciones de transporte y de acceso a actividades resulta esencial, especialmente, en ciudades latinoamericanas caracterizadas por la segregación socioespacial y la inequidad social (Comisión Económica para América Latina y el Caribe [CEPAL], 2016; Deneulin, \& SánchezAncochea, 2018; Iglesias et al., 2019; Vecchio et al., 2020).

Uno de los mecanismos que pueden mejorar la accesibilidad de los grupos más vulnerables consiste en la definición de zonas donde se obliga o incentiva la construcción de vivienda asequible a través de distintos cuerpos normativos, lo que se ha utilizado en diferentes partes del mundo, tanto para mejorar la localización como aumentar su stock ${ }^{1}$. En el caso de Chile, recientemente se aprobó el Decreto $\mathrm{N}^{\circ} 56^{2}$, que le entrega al Ministerio de la Vivienda y Urbanismo (Minvu) la atribución de otorgar beneficios de normas urbanísticas para proyectos que incorporen vivienda subsidiada en ciertas zonas de las ciudades. El objetivo de estos incentivos normativos es la construcción de viviendas asequibles en barrios con buena accesibilidad, permitiendo incrementar la capacidad máxima de edificación de los predios a cambio de exigencias en la composición de los proyectos inmobiliarios ${ }^{3}$.

En paralelo, el gobierno de Chile está tramitando un proyecto de ley de "Integración Social y Urbana". Este cuerpo normativo propone profundizar el mecanismo de incentivos, a fin de complementarlo con otro tipo contraprestaciones. Ya fue aprobado por la Cámara de Diputados y, en su conjunto, ha sido sometido a observaciones y críticas por parte de diversos actores y organizaciones (Bannen et al., 2019; Centro de Políticas Públicas UC, 2019; Gasic, 2019; Razmilic y Larraín, 2019). Actualmente, este proyecto de ley se encuentra en la discusión legislativa del Senado del país.

Dentro de este debate, una dimensión que no ha tenido suficiente atención son los criterios de accesibilidad que deberá cumplir una zona particular para que sea elegible y pueda recibir los beneficios normativos. El reglamento define que estos incentivos solamente se podrán aplicar en polígonos determinados que cumplan condiciones de proximidad a infraestructura de transporte y equipamiento urbano (Artículo 6.6.2 del Decreto $\mathrm{N}^{\circ} 56$ ). Por otra parte, otros actores nacionales relevantes también han elaborado propuestas sobre las condiciones que debieran cumplir las zonas para que puedan ser densificadas con integración social. En este sentido, la definición de los criterios de accesibilidad es fundamental, pues uno de los objetivos centrales de la política es mejorar sustantivamente la localización de las viviendas sociales que se construyen en las ciudades, para así facilitar su integración y acceso a las oportunidades urbanas.

Por lo tanto, el objetivo general de este trabajo es analizar críticamente los criterios de accesibilidad propuestos por: 1) el Gobierno de Chile; 2) el proyecto "Ciudad con Todos" liderado por el Centro de Políticas Públicas UC; y 3) el Consejo Nacional de Desarrollo Urbano (CNDU) para las zonas donde se promoverá o favorecerá la densificación con integración social en Chile. En particular, este trabajo busca reconocer aquellos criterios problemáticos o ausentes en estas propuestas, con el objetivo de complementar y sugerir modificaciones

1 Ver Centro de Políticas Públicas UC, 2016 para una revisión de diversos ejemplos en el mundo.

2 Este decreto corresponde a un reglamento del artículo $3^{\circ}$ de la Ley $\mathrm{N}^{\circ} 20.741$ sobre copropiedad inmobiliaria.

3 El reglamento define una serie de condiciones para la aplicación de esta política: la composición necesaria de los proyectos para considerarse integrados, las normas urbanísticas sobre las que se podrán entregar beneficios, el procedimiento según el cual estas se entregarán, los diferentes roles y responsabilidades de los actores involucrados, entre otros. 
que permitan definir de mejor forma aquellas zonas receptoras de densificación con integración.

Nuestra hipótesis es que la discusión en torno a los criterios de accesibilidad a cumplir por las zonas de integración urbana ha sido reducida a la dimensión de proximidad, sin comprender la complejidad de la relación entre uso de suelo, transporte y nivel de servicio. Para testear esta hipótesis y abordar las preguntas antes descritas, se propone un marco de análisis a partir de la literatura nacional e internacional, estableciendo dimensiones que reflejen las diferentes condiciones de entorno urbano, accesibilidad y densidad que debiera considerar la localización de la vivienda asequible. A partir de estas dimensiones, se evalúan las diferentes propuestas, simulando algunos de sus criterios para la ciudad de Santiago de Chile y comparando el cumplimiento de nuevos criterios en distintas zonas de esta. A partir de esto, se discuten los resultados, sugiriendo algunos estándares y posibles modificaciones a las condiciones de accesibilidad descritas en el Decreto $\mathrm{N}^{\circ} 56$. El artículo finaliza con la exposición de las principales conclusiones, limitaciones y futuras líneas de investigación.

\section{Marco teórico}

Las ciudades de América Latina y el Caribe enfrentan importantes problemas de vivienda asociados con los bajos ingresos, oferta insuficiente y altos precios, lo que lleva a la construcción de viviendas informales y a la falta de servicios básicos como agua y servicios sanitarios (Banco Interamericano de Desarrollo [BID], 2012). En Santiago de Chile, Espinoza y Urzúa (2018) muestran que los precios de venta casi se han duplicado en el período 2009-2017 y que los precios de alquiler han aumentado aproximadamente un $50 \%$ en el mismo período.

Este escenario puede explicarse por diversas políticas públicas implementadas en el pasado (Programa de las Naciones Unidas para el Desarrollo [PNUD], 2016). Desde 1980 , los asentamientos informales de bajos ingresos y las viviendas sociales fueron desplazados de las áreas centrales y de altos ingresos hacia la periferia (Molina, 1986; Morales y Rojas, 1987; Tapia, 2011), dando origen a un desarrollo urbano desigual. Esta situación impulsa a la política de vivienda para que vele por la integración social en el territorio, asegurando además de una vivienda asequible, que esta tenga adecuados niveles de acceso a oportunidades.

Para abordar estos objetivos, se han propuesto y ejecutado diferentes programas y políticas de integración urbana en el mundo (Brain, 2014). En casos como el americano, donde es posible encontrar guetos o altos niveles de exclusión urbana, se busca mejorar las condiciones de acceso a oportunidades y una mayor inclusión de grupos vulnerables en la sociedad (Fraser et al., 2013). Por otro lado, otras estrategias consideran una mayor planificación que facilite una mezcla de grupos socioeconómicos en un contexto que permita conciliar buen acceso y conciencia medioambiental (Bailey et al., 2006; Lelévrier, 2013).

En este contexto, uno de los mecanismos más utilizados corresponde a la zonificación inclusiva (Centro de Políticas Públicas UC, 2016), cuyo propósito es la regulación de ciertos sectores de las ciudades para generar oferta de vivienda asequible. Un ejemplo latinoamericano de ello son las zonas de interés social especial (ZEIS) de Sao Paulo, donde se estimula la producción de viviendas para personas de bajos ingresos mediante exenciones tributarias o transferencia de derechos de construcción (Budds, \& Teixeira, 2005). Otra forma frecuente de zonificación inclusiva es incentivar el desarrollo de proyectos de vivienda con integración social a cambio de beneficios de normas urbanísticas. Uno caso conocido es el llamado Capitulo 40B del estado de Massachussetts (Estados Unidos), donde se entregan beneficios en la densidad de los proyectos inmobiliarios cuando cierto porcentaje de sus viviendas son consideradas "económicas" (Hananel, 2014).

Como mencionamos en la sección anterior y profundizaremos luego, en este tipo de políticas es clave que las zonas donde se exige o incentiva la construcción de vivienda social cumplan con adecuados estándares de accesibilidad y densificación. La experiencia internacional muestra que no es siempre así: por ejemplo, el Capítulo 40B se aplica a todos los municipios que incumplan 
ciertos criterios de integración social, sin considerar otro tipo de estándares. Las ZEIS de Sao Paulo, en cambio, pueden exigir también la construcción de infraestructura y servicios o asegurar que un territorio céntrico no está lo suficientemente desarrollado.

En Chile, además del Decreto $\mathrm{N}^{\circ} 56$ ya mencionado, otros actores también han elaborado propuestas acerca de las condiciones que debieran cumplir las zonas para que puedan ser densificadas con integración social. En primer lugar, se ubica el proyecto "Ciudad con Todos" nacido en una colaboración entre el Centro de Políticas Públicas UC y los desarrolladores inmobiliarios. Su objetivo durante el año 2019 fue aportar con evidencia, diagnósticos y propuestas para una densificación equilibrada. Para ello, se elaboró un reporte donde se definen zonas de buena accesibilidad (ZBA), como aquellos territorios aptos para ser densificados y, por lo tanto, donde se podría promover la integración social (Centro de Políticas Públicas UC y Asociación de Desarrolladores Inmobiliarios, 2019a).

En segundo lugar, existe una propuesta que proviene del Consejo Nacional de Desarrollo Urbano (CNDU) (2019), un órgano consultivo y asesor del Estado que presenta reformas urbanas coherentes con la Política Nacional de Desarrollo Urbano de Chile. Durante el año 2019, el CNDU publicó un documento con propuestas para la integración social en las ciudades chilenas, donde plantea establecer zonas de integración social en sectores urbanos consolidados, que operarían de forma muy similar a los polígonos de integración social del Decreto $\mathrm{N}^{\circ} 56$. En esta propuesta, también sugieren criterios para definir estas zonas, asociados tanto a su composición socioeconómica como a su accesibilidad a servicios y equipamiento.

Para analizar cada una de las tres propuestas, utilizamos un marco de referencia con distintas dimensiones de accesibilidad y densificación. Estas se basan en la literatura clásica y emergente sobre accesibilidad, con el objeto de comprender las dimensiones que debieran considerarse al momento de evaluar el acceso al transporte público y a las oportunidades urbanas. De este modo, podemos identificar tres dimensiones:
1. Accesibilidad al transporte público: refiere a las condiciones de proximidad al transporte público y del territorio alcanzable (o cobertura) a través de él. Muchos de los estudios en este tema se centran solo en el acceso a estaciones o paradas (Lei, \& Church, 2010; Mamun et al., 2013; Mavoa et al., 2012), estableciendo umbrales de acceso diferenciados para el caso de buses, metro o trenes. Estas métricas se centran solo en una medida agregada para la oferta de transporte y, usualmente, carecen de información detallada acerca de las frecuencias o la cobertura geográfica que proveen, salvo indicadores más complejos como el PTAL (Wu, \& Hine 2003). Por esto, resulta necesario no solo considerar el acceso al sistema, sino también, de manera complementaria, la accesibilidad a oportunidades urbanas y la calidad del entorno urbano caminable (Rossetti et al., 2019; Tiznado-Aitken et al., 2018). Como propone Hernandez (2018), se deben incluir discusiones acerca del nivel de servicio del transporte público. En esta línea, Arbex y Cunha (2020) plantean que la accesibilidad debe integrar una función de costo generalizada completa que considere la percepción del tiempo de caminar o esperar.

2. Accesibilidad a oportunidades: refiere a las condiciones de proximidad y acceso a equipamiento y oportunidades urbanas, alcanzables a través de caminata, transporte público u otro modo de transporte. La idea de acceso en lugar de la mera movilidad como el objetivo principal de la planificación de transporte ha ganado consenso en la literatura (Handy, 2020; Martens, 2017), dada su contribución a la inclusión social (Lucas, 2012) y la posibilidad de participar de actividades de empleo, educación, salud, ocio y recreación, entre otras. De este modo, su estudio mediante diversos modos de transporte es esencial. La literatura internacional ha mostrado avances en evaluar modos de transporte activo o no motorizado (Chin et al., 2008; Iacono et al., 2010; Vale et al. 2015), transporte público (Mamun et al., 2013; Polzin et al., 2002; Ryus et al., 2000) e incluso comparaciones entre modos, como automóvil privado y transporte público (Benenson et al., 2011; Kawabata, 2009; Lovett et al., 2002), lo que permite realizar un análisis más completo. 
Tabla 1

Propuestas y criterios para las zonas de integración urbana en Chile

\begin{tabular}{|c|c|c|c|}
\hline & & CNDU & Ciudad con Todos: ZBA \\
\hline $\begin{array}{l}\text { Accesibilidad a } \\
\text { transporte público }\end{array}$ & $\begin{array}{l}\text { Alguna de las siguientes condiciones: } \\
\text { 1.Paraderos de servicios segregados } \\
\text { del tránsito vehicular (construidos, en } \\
\text { ejecución o con presupuesto asignado) } \\
\text { a menos de } 700 \text { metros. } \\
\text { 2. Ejes estructurantes con oferta significativa } \\
\text { de transporte público a menos de } 500 \\
\text { metros. } \\
\text { 3. Paradero de transporte público, taxi } \\
\text { buses, taxis colectivos: a menos de } \\
500 \text { metros. Si aplica este criterio } \\
\text { debe cumplir además el criterio de } \\
\text { accesibilidad a equipamiento. }\end{array}$ & & $\begin{array}{l}\text { Alguna de las siguientes condiciones: } \\
\text { - Paraderos a un máximo de } 300 \text { metros. } \\
\text { - Estaciones de metro o intermodales a un } \\
\text { máximo de } 600 \text { metros. }\end{array}$ \\
\hline $\begin{array}{l}\text { Accesibilidad a } \\
\text { oportunidades }\end{array}$ & $\begin{array}{l}\text { Solo aplica si se utiliza el punto } 3 \text { de } \\
\text { accesibilidad al transporte público. En } \\
\text { ese caso, debe cumplir una distancia } \\
\text { máxima de } 500 \text { metros respecto de a lo } \\
\text { menos cuatro equipamientos o espacios } \\
\text { públicos, tales como: } \\
\text { 1. Establecimiento educacional (básica/ } \\
\text { media). } \\
\text { 2. Establecimiento de salud de la red } \\
\text { asistencial pública. } \\
\text { 3. Establecimiento comercial de } \\
\text { compraventa de mercaderías diversas. } \\
\text { 4. Equipamiento de servicios que presten } \\
\text { un servicio público. } \\
\text { 5. Equipamiento deportivo o de cultura } \\
\text { gratuito o de valor accesible. } \\
\text { 6. Parque o área verde superior a } 5 \text { mil m². } \\
\text { 7. Los equipamientos } 1,2,5 \text { y } 6 \text { podrían } \\
\text { solamente tener permisos, estar } \\
\text { ejecución o con presupuesto asignado. } \\
\text { 8. Se admitirá que una de las cinco } \\
\text { distancias máximas antes referidas } \\
\text { pueda superar los } 500 \text { metros, aunque } \\
\text { siempre inferior a } 1.000 \text { metros. }\end{array}$ & $\begin{array}{l}\text { Educación primaria a menos de } 500 \\
\text { metros (existente o con financiamiento } \\
\text { programado). } \\
\text { Salud primaria a menos de } 1.500 \\
\text { metros (existente o con financiamiento } \\
\text { programado). } \\
\text { Servicios o comercio: a menos de } 500 \\
\text { metros (existentes o se encuentren en } \\
\text { construcción, densidad } 600 \mathrm{~m} 2 / \mathrm{ha} \text { ). } \\
\text { Plazas o parques públicos: a menos de } 500 \\
\text { metros (existentes o con financiamiento } \\
\text { programado). } \\
\text { Centros de trabajo y centros de estudios de } \\
\text { educación técnica y superior: a menos de } 30 \\
\text { minutos en transporte público. }\end{array}$ & $\begin{array}{l}\text { Educación primaria: a menos de } 500 \text { metros. } \\
\text { Salud: a menos de } 1.500 \text { metros. } \\
\text { Áreas verdes: alguna de las siguientes } \\
\text { condiciones: } \\
\text { - A menos de } 500 \text { metros para plazas. } \\
\text { - A menos de } 5.000 \text { metros para parques } \\
\text { (más de } 1 \text { ha). }\end{array}$ \\
\hline \multirow{3}{*}{$\begin{array}{l}\text { Capacidad de } \\
\text { carga }\end{array}$} & \multirow{3}{*}{$\begin{array}{l}\text { No hay criterios específicos. Informe de } \\
\text { potencial urbano debe justificar el número } \\
\text { de habitantes admitidos por el sector. }\end{array}$} & $\begin{array}{l}\text { Transporte público: estándar suficiente para } \\
\text { la demanda potencial. } \\
\text { Educación primaria: matrículas disponibles } \\
\text { superiores a la demanda potencial. }\end{array}$ & $\begin{array}{l}\text { Áreas verdes: máximo } 3,43 \mathrm{~m}^{2} / \text { hab para } \\
\text { un área de influencia de } 500 \text { metros para } \\
\text { plazas y } 5.000 \text { metros para parques de más } \\
\text { de una ha. }\end{array}$ \\
\hline & & $\begin{array}{l}\text { Salud primaria: capacidad ociosa (jornadas } \\
\text { médicas/ } 1.000 \text { hab) a la demanda potencial. }\end{array}$ & $\begin{array}{l}\text { Educación primaria: máximo } 0,75 \\
\text { matrículas por habitante para un área de } \\
\text { influencia de } 400 \text { metros. }\end{array}$ \\
\hline & & $\begin{array}{l}\text { Plazas y parques públicos: } \\
\text { superficie de plazas y parques públicos: } \\
\text { máximo de } \mathrm{m} 2 \text { por habitante considerando } \\
\text { la demanda potencial. }\end{array}$ & $\begin{array}{l}\text { Salud primaria: máximo } 0,5 \text { cupos en } \\
\text { establecimientos por habitante para un área } \\
\text { de influencia de } 1.500 \text { metros. }\end{array}$ \\
\hline
\end{tabular}

Nota: Tabla elaborada a partir de CNDU (2019), Decreto Nº 56 y el Centro de Políticas Públicas UC y Asociación de Desarrolladores Inmobiliarios (2019b).

3. Capacidad de carga: refiere a la capacidad poblacional del territorio. En otras palabras, otorga una relación entre la oferta entregada (equipamiento urbano y servicios) y la demanda potencial de la población por tales oportunidades ofrecidas. A pesar de que la idea de que los indicadores de accesibilidad consideren la competencia por ellas es antigua (Shen, 1998), pocas aplicaciones se observan en la literatura (ver, por ejemplo, Merlin, \& Hu, 2017 y Moreno-Monroy et al., 2018), particularmente en el caso Latinoamericano (Vecchio et al., 2020). Asimismo, el efecto de la carga del transporte público, es decir, del hacinamiento en el acceso a oportunidades mediante transporte público usualmente no se considera, siendo que puede llegar a disminuir en un $57 \%$ el acceso a oportunidades (Arbex, \& Cunha, 2020).

Considerando esta clasificación, analizamos los criterios propuestos por el reglamento asociado al Decreto $\mathrm{N}^{\circ}$ 56, el CNDU y el proyecto "Ciudad con Todos". Estos se encuentran en la Tabla 1. 


\section{Metodología}

Considerando el marco de análisis y los estándares definidos por cada una de las propuestas, realizamos un análisis crítico sobre la base de los avances en la literatura sobre geografía de transporte y accesibilidad. Para ello, la metodología utilizada consistió en:

Analizar los criterios propuestos y simular algunos de sus resultados a través de herramientas SIG. Para ello, se utilizó información abierta y georreferenciada sobre el transporte público, en particular, la localización de la infraestructura de transporte (estaciones de Metro y paraderos de buses) así como información de los viajes realizados a partir de la matriz de viajes obtenida desde la tarjeta Bip! y programas de operación de Transantiago (Directorio Transporte Público Metropolitano [DTPM], 2015, 2019; TiznadoAitken et al., 2021). Asimismo, utilizamos información georreferenciada sobre equipamiento y servicios de la ciudad de Santiago, en particular, la localización de establecimientos educacionales (Ministerio de Educación [Mineduc], 2016, 2017), áreas verdes (IDE Observatorio Ciudades UC [OCUC], 2019) y equipamiento cultural (Centro de Desarrollo Urbano Sustentable [CEDEUS], 2015; OCUC, 2020). Estos datos fueron procesados utilizando el software abierto QGIS, donde se pueden aplicar las diferentes condiciones y conocer qué zonas de la ciudad cumplen con los estándares propuestos por el Gobierno de Chile, el CNDU y el Centro de Políticas Públicas UC.

A partir del análisis y simulación de criterios, examinamos las zonas que poseen las condiciones de las distintas propuestas y estudiamos si cumplen o no con otros criterios relevantes derivados de la literatura especializada, de modo de asegurar adecuados niveles de accesibilidad a transporte público, capacidad de carga y accesibilidad a oportunidades urbanas.

A la luz del análisis realizado en los dos pasos previos, proponemos estándares y posibles modificaciones a las condiciones de accesibilidad descritas en el Decreto $\mathrm{N}^{\circ}$ 56 , focalizándonos en las tres dimensiones mencionadas en el marco teórico.

\section{Resultados}

Para observar aciertos e insuficiencias de los criterios propuestos para la densificación e integración social (Tabla 1), se presentan tres subsecciones que sintetizan los principales resultados.

Transporte público y oportunidades urbanas como dimensiones excluyentes

Una primera observación es la tendencia de las propuestas a considerar las dimensiones de accesibilidad a transporte público y la accesibilidad a equipamiento y oportunidades urbanas como excluyentes. Esto queda en evidencia en el Decreto $\mathrm{N}^{\circ} 56$, donde se formulan criterios para ambas dimensiones, pero de manera que el cumplimiento de una exime el cumplimiento de la otra. En este documento no aplican los criterios de acceso a equipamiento cuando existe acceso a transporte público de alta frecuencia o con prioridad, y solo se mantienen las mínimas condiciones de transporte público si es que aplican aquellas de equipamiento. Por otra parte, en la propuesta del CNDU simplemente se opta por estándares de equipamiento, ignorando aquellas asociadas al transporte público. Una posible razón de esto es la valoración del acceso a los bienes públicos urbanos, asumiendo que estos podrían alcanzarse indistintamente vía distancias "caminables" (proximidad territorial) o vía transporte público. Por tanto, bastaría que se cumpla alguna de estas dos condiciones para que el acceso a los bienes públicos esté cubierto. Sin embargo, este análisis presenta ciertas deficiencias.

En primer lugar, el acceso caminable a equipamiento no es sustituto del acceso a las oportunidades a las que se puede acceder vía transporte público. Esto es especialmente cierto en ciudades fuertemente segregadas como Santiago, donde las oportunidades de una determinada calidad están lejos de estar homogéneamente distribuidas en la ciudad. Asimismo, el transporte público resulta esencial para aquellas personas que poseen movilidad reducida y, por ende, no tienen el mismo acceso mediante modos activos como la caminata. Así, el transporte público es una fuente de movilidad que cumple diversos propósitos. Por un lado, aquellos motivos que permiten la participación en 
A)

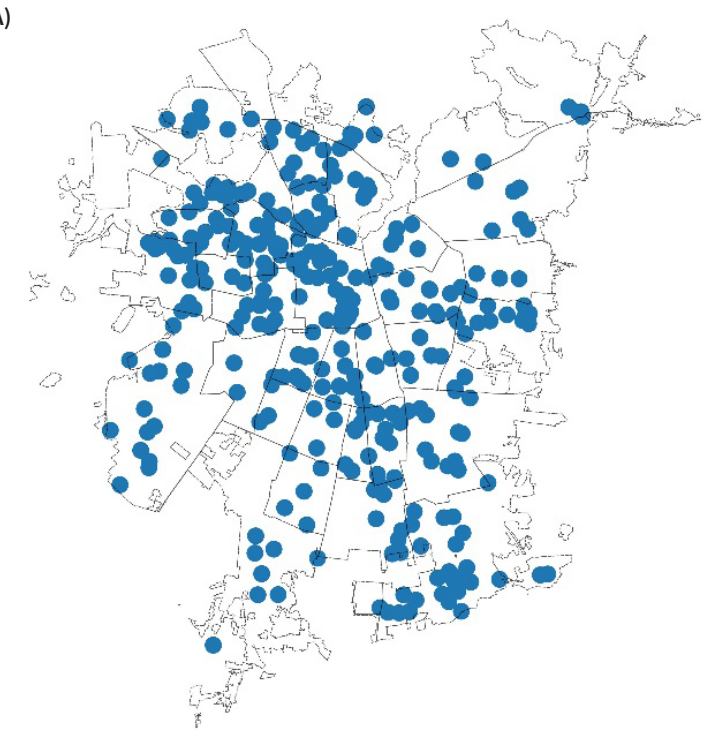

B)

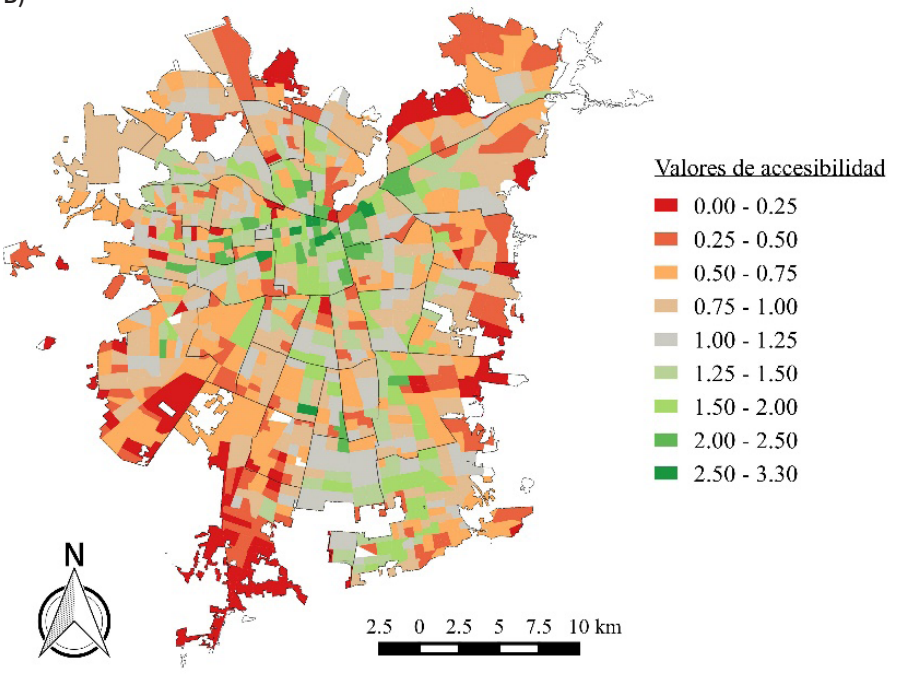

Nota: a) A la izquierda, un buffer de 500 metros de accesibilidad en torno a la matrícula de educación pública gratuita de calidad en Santiago, según lo propuesto por el CNDU. b) A la derecha, las zonas de la ciudad que tienen buena accesibilidad a estos establecimientos mediante transporte público, considerando competencia y percepción del nivel de servicio. Mapas elaborados sobre la base de Mineduc (2016, 2017) y Tiznado-Aitken et al. (2021).

sociedad y evitan la exclusión social (Lucas, 2012), como por ejemplo visitar familiares y amigos, lugares de ocio como cines, bares y restaurantes, o centros culturales. Por otro lado, los propósitos obligatorios de viaje tienen un rol esencial, donde el ejemplo del trabajo o estudio son los más recurrentes. Para ilustrar lo anterior, se pueden comparar los mapas de la Figura 1. Es posible observar que, en la zona demarcada, correspondiente a la comuna de Maipú, no necesariamente coinciden los estándares propuestos por el CNDU (Figura 1a) con aquellos de una buena accesibilidad (Figura $1 b$ ), ya que en la mayoría de estas zonas existe un déficit de acceso a la educación de entre $50 \%$ y $75 \%$ (valores entre 0,25 y 0,5 , según el mapa).

En segundo lugar, el acceso al transporte público no es sustituto de la accesibilidad caminable a equipamiento. Existen zonas con relativamente buena conectividad al transporte público que carecen de equipamiento urbano caminable. Dado que caminar es parte de nuestra naturaleza, si el espacio en torno a nuestras actividades invita a caminar, nuestra salud y percepción de la calidad de vida mejora sustancialmente (Sarmiento et al., 2010). Por ejemplo, si analizamos las áreas verdes en Santiago (Figura 2), observamos que zonas centrales o pericentrales en Santiago, Quinta Normal o Estación
Central poseen un bajo acceso a áreas verdes (Figura $2 b)$, a pesar de que cuentan con una buena provisión de transporte público (Figura 2a). Esto podría acentuarse si se considera una diferenciación por calidad y estado de las áreas verdes. De hecho, más del 40 \% de las áreas verdes son desafectadas y el $28 \%$ se encuentra en mal estado (OCUC, 2019).

\section{Accesibilidad al transporte público: criterios insuficientes}

Si observamos los criterios de accesibilidad al transporte público de todas las propuestas analizadas, se distingue un solo tipo de estándar: proximidad territorial a paraderos de transporte público, que se traduce en una distancia "caminable" a partir de diferentes áreas de influencia. El único componente adicional - presente en el Decreto $\mathrm{N}^{\circ}$ 56- consiste en aumentar la distancia admitida de acuerdo con la importancia del paradero (por ejemplo, una estación de Metro tendría un área de influencia mayor que un paradero de bus).

Esta aproximación a la accesibilidad es bastante limitada, ya que no incorpora otras variables fundamentales de la experiencia de viaje mediante transporte público (Lucas et al., 2016; Martens, 2017), como la calidad 
A)

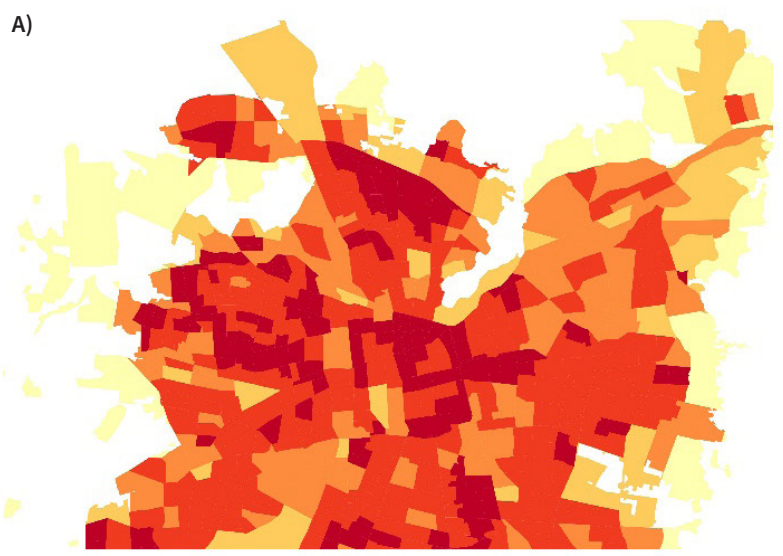

B)

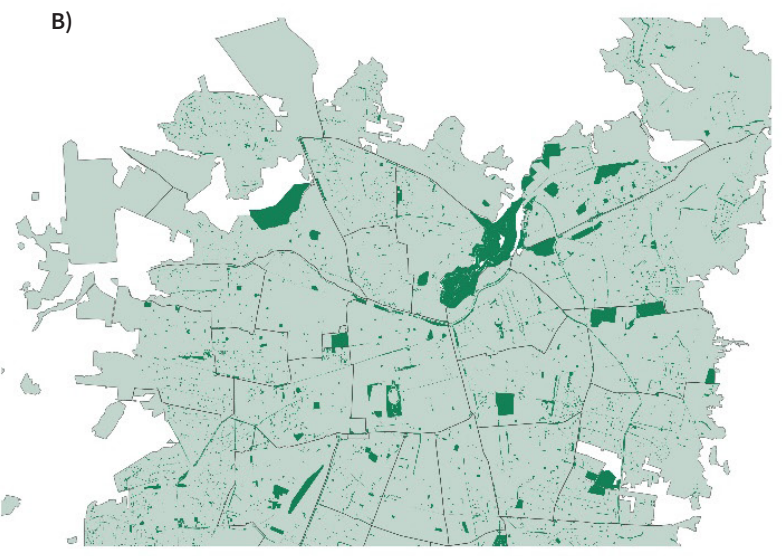

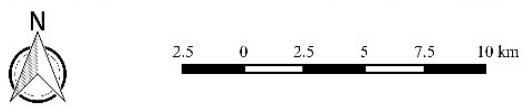

Nota: a) A la izquierda la accesibilidad a paradas de transporte público (colores más rojos, mejor acceso). b) A la derecha, distribución de áreas verdes en la ciudad en color verde. Mapas elaborados sobre la base de Tiznado-Aitken et al. (2018) y OCUC (2019).

del entorno caminable (Tiznado-Aitken at al., 2018); el tiempo de espera; la comodidad al interior del vehículo; el número de transbordos (Currie, 2004; Tiznado-Aitken et al., 2017); la congestión; confiabilidad del tiempo de viaje; y horarios de atención para diferentes servicios (Delafontaine et al., 2011; Fransen et al., 2015; Neutens et al., 2012; Weber, \& Kwan, 2002).

Para ilustrar el punto, veamos los criterios de la dimensión de transporte que define "Ciudad con Todos" a través de las ZBA. Como se observa en la Tabla 1, esta asume que se tiene una accesibilidad adecuada cuando se cumple alguna de estas condiciones:

- Paraderos a un máximo de 300 metros.

- Estaciones de metro o intermodales a un máximo de 600 metros.

Sin embargo, de acuerdo con el programa de operación de Transantiago del primer semestre de 2019, el $30 \%$ de las paradas de buses son visitadas solo por un servicio (DTPM, 2019). De estas paradas de buses, 115 cubren una zona de influencia de 300 metros de radio que cumpliría con el criterio definido por ZBA (Figura 3). Sin embargo, la oferta de transporte público para estas zonas estaría lejos de ser suficiente. Algunas zonas problemáticas bajo el criterio de ZBA se pueden observar en la Tabla 2. En las comunas de Ñuñoa, San Joaquín y Lo Prado vemos zonas que solo poseen una parada de transporte público, con un recorrido de buses y lejos del Metro, lo que impide un acceso adecuado a oportunidades.

Por último, existen múltiples puntos que pueden cumplir con todos los criterios de transporte público propuestos (aun cuando sea distancia caminable), pero que no poseen un estándar mínimo de calidad del entorno urbano por el cual se debe caminar. Para ilustrar lo anterior, en la Figura 4 se muestran las zonas de Santiago que observan el criterio de transporte público de las ZBA y la calidad del entorno urbano. Se evidencia que en muchas zonas de la ciudad estas no coinciden: una distancia caminable a un paradero no implica que su acceso sea seguro, limpio, con mobiliario urbano adecuado o buena calidad de infraestructura peatonal. Particularmente, la zona sur de Santiago (marcada en color morado) cumple con el criterio ZBA (Figura 4a), pero posee un bajo nivel de calidad de entorno urbano (Figura 4b). Considerar elementos de la "calidad de la caminata" (Cheng, \& Chen, 2015), a través de infraestructura, belleza, mobiliario, seguridad y limpieza, puede ser clave en la experiencia de viaje, y, por ende, permite una correcta integración de grupos vulnerables a zonas que ofrezcan garantías en el acceso a oportunidades. 
Figura 3

Accesibilidad al transporte público y frecuencia de recorridos de buses

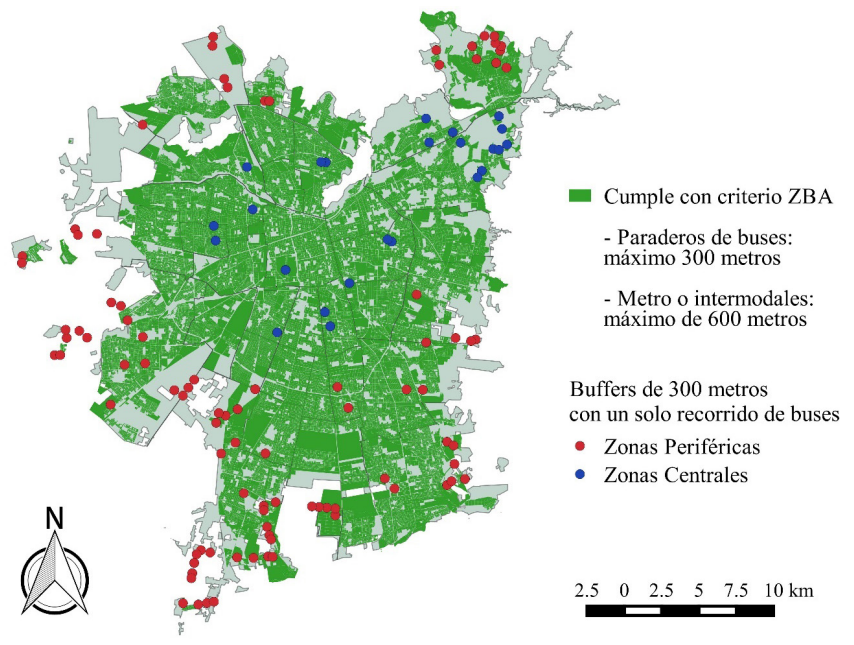

Nota: Criterio de transporte de ZBA y paradas de transporte público que sirven a zonas de 300 metros con un solo recorrido. Mapa elaborado sobre la base de DTPM (2019) y Centro de Políticas Públicas UC y Asociación de Desarrolladores Inmobiliarios (2019b), de Tiznado-Aitken et al. (2018) y OCUC (2019).

Figura 4

Accesibilidad al transporte público y calidad del entorno urbano

A)

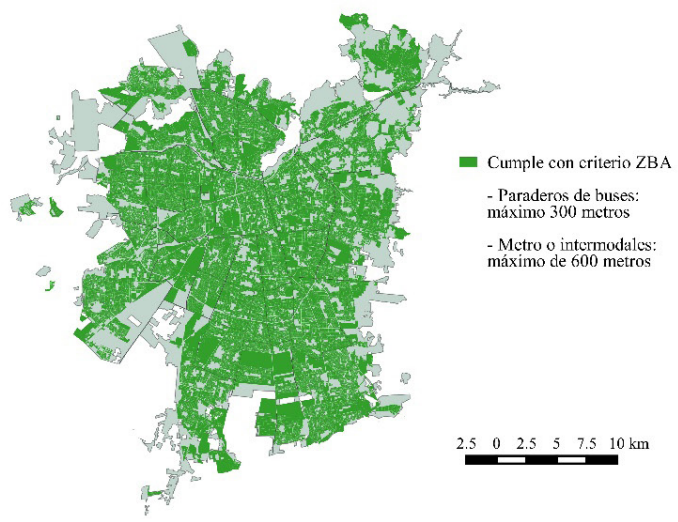

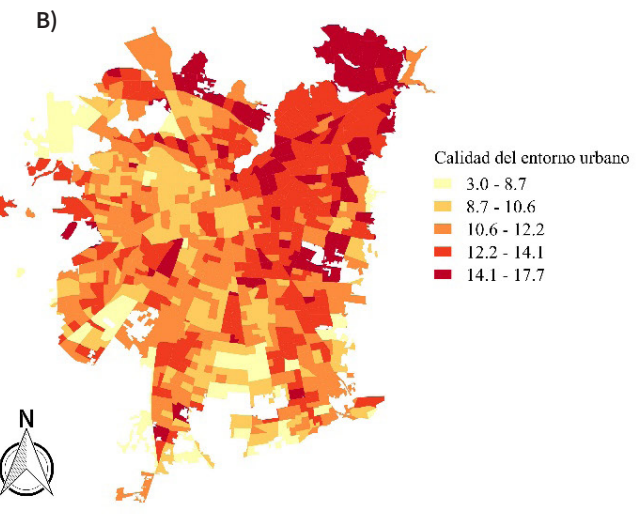

Nota: a) A la izquierda, las zonas que cumplen con criterio de transporte ZBA. b) A la derecha, la calidad del entorno urbano basado en variables de limpieza, seguridad, mobiliario urbano y calidad de infraestructura peatonal con información del Instituto Nacional de Estadística [INE] (2011). Mapas elaborados sobre la base de Tiznado-Aitken et al., 2018.

Tabla 2

Paraderos con baja frecuencia de buses

\begin{tabular}{|c|c|c|c|c|}
\hline Paradero & Recorridos de buses & Comuna & Frecuencia & Cercanía al Metro \\
\hline PD1034 & D09 & Ñuñoa & Un bus cada 10 minutos & Ñuñoa (a 28 minutos) \\
\hline PD1035 & D09 & Ñuñoa & Un bus cada 10 minutos & Ñuñoa (a 27 minutos) \\
\hline PH509 & $\mathrm{H} 05$ & San Joaquín & Un bus cada 15 minutos & $\begin{array}{l}\text { Carlos Valdovinos (a } 26 \\
\text { minutos) }\end{array}$ \\
\hline PH775 & H09 & San Joaquín & Un bus cada 15 minutos & $\begin{array}{l}\text { Carlos Valdovinos (a } 26 \\
\text { minutos) }\end{array}$ \\
\hline PJ756 & J06 & Lo Prado & Un bus cada 10 minutos & Pajaritos (a 16 minutos) \\
\hline PJ1037 & J06 & Lo Prado & Un bus cada 12 minutos & Pajaritos (a 10 minutos) \\
\hline
\end{tabular}




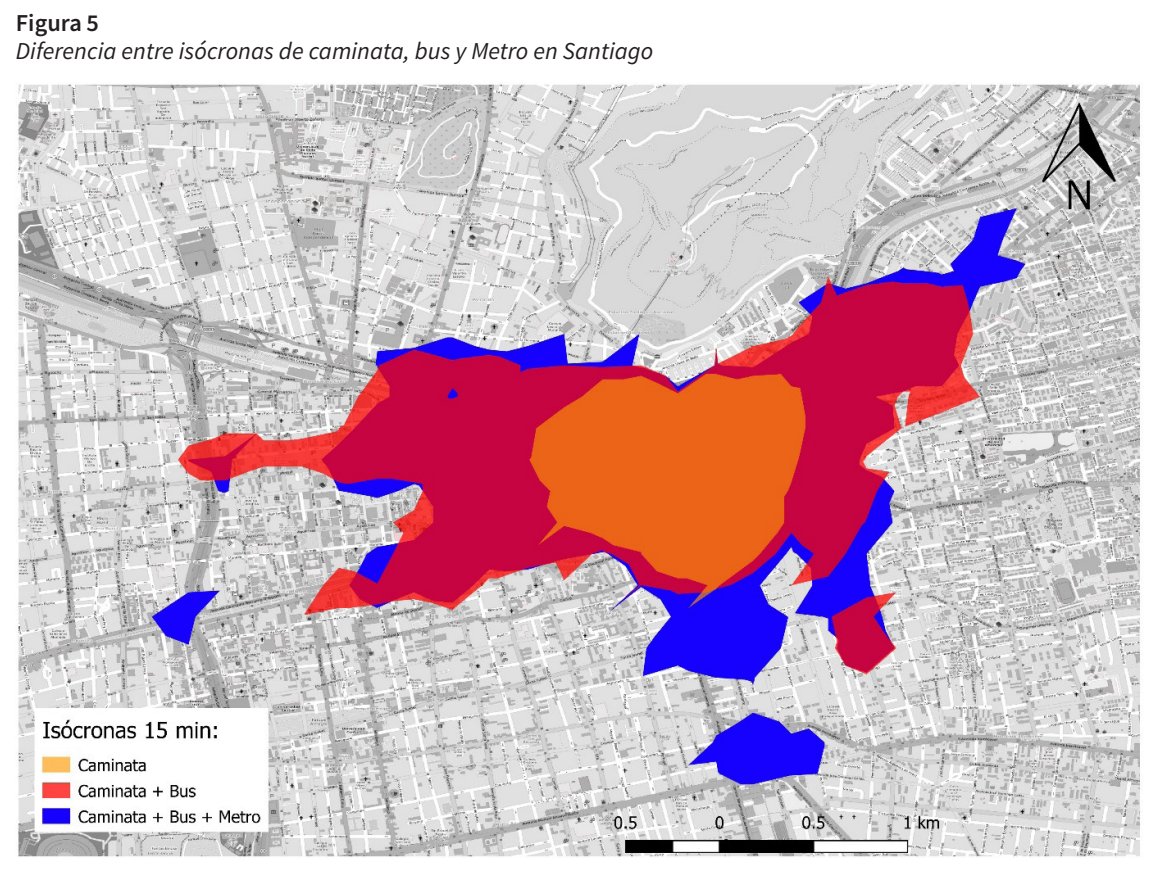

Nota: Mapa elaborado sobre la base de DTPM (2019).

\section{Acceso a equipamiento: visión limitada del transporte, capacidad de carga y calidad de oportunidades}

Al igual que la accesibilidad al transporte público, todas las propuestas analizadas utilizan una "distancia máxima caminable" como criterio que determina el acceso a un equipamiento homogéneo de cualquier tipo. Es decir: el equipamiento estaría disponible o no (como una variable discreta) en la medida en que la distancia a la que se encuentra no supere cierto umbral.

Un primer reparo está, nuevamente, en homologar la accesibilidad solo a la distancia caminable. Los parques urbanos, establecimientos de salud o centros de educación podrían estar asociados también a una accesibilidad razonable en transporte público. En otras palabras, no parece ser más accesible un área verde ubicada a 500 metros, en un entorno inseguro, que otra accesible en 15 minutos en transporte público. Los estándares del CNDU intuyen lo anterior cuando proponen criterios para centros de trabajo y educación superior, donde definen un estándar de tiempo en transporte público para cumplir con su condición de accesibilidad. Para ilustrar lo anterior, se muestra la diferencia en términos de superficie alcanzable en 15 minutos utilizando caminata o bus (Figura 5).
Un segundo reparo es que las propuestas no incorporan la variable de calidad del equipamiento, lo que es problemático en cuanto la accesibilidad está fuertemente condicionada por esta dimensión (Vecchio et al., 2020). Ciertamente, no son equivalentes zonas que tienen disponibles colegios de excelencia con aquellas que solo cuentan con colegios deficientes en términos de calidad e infraestructura. De esta forma, avanzar en criterios que permitan clasificar las oportunidades sobre la base su calidad y oferta efectiva es esencial.

Por último, para analizar la capacidad de carga de un polígono, se propone considerar tres dimensiones: 1) la carga urbana o de densificación; 2) la carga al interior del transporte público; y 3) la carga del equipamiento urbano. Cada una por sí sola es importante para definir si existe capacidad efectiva para el eventual aumento de población.

Por carga urbana se entiende aquella que indica la densidad adecuada que un barrio podría recibir dado sus condiciones geográficas y urbanas. El Decreto $\mathrm{N}^{\circ} 56$ es el único que avanza en este sentido, exigiendo un informe de potencial urbano que justifique la densificación adecuada del polígono propuesto. Este punto es relevante, porque existen una serie de zonas que, a pesar de contar con capacidad disponible de transporte público y equipamiento, presentan barrios o inmuebles patrimoniales, zonas de riesgo u otras condiciones que limitan su eventual densificación. 


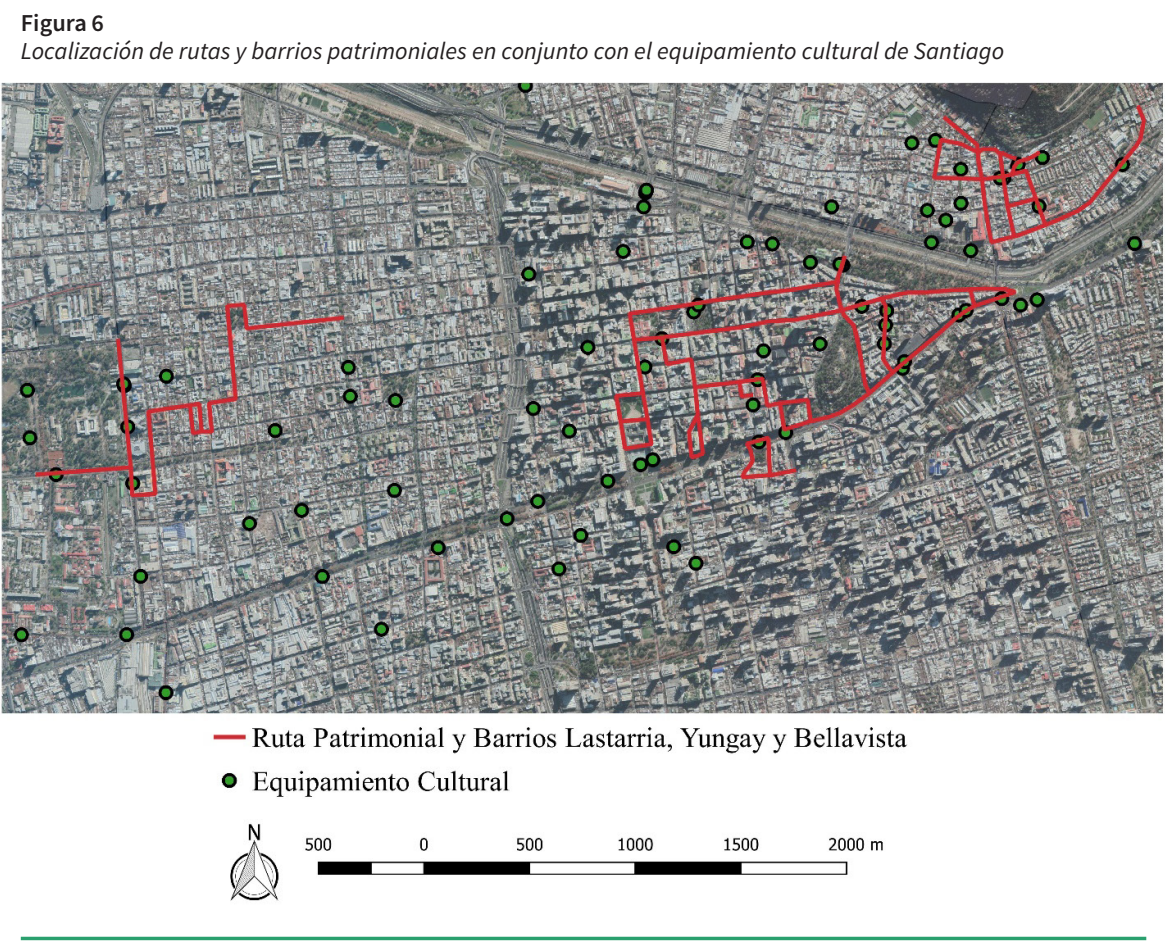

Nota: Mapa elaborado sobre la base de CEDEUS (2015) y OCUC (2020).

A pesar de que es deseable que la localización posea una buena accesibilidad a equipamiento cultural, se debe tener en cuenta barrios patrimoniales como Bellavista, Lastarria, Yungay, entre otros (Figura 6), que cumplen con las condiciones del decreto, pero donde no se debiera poder densificar.

Cuando analizamos las restricciones de capacidad de carga del transporte público, observamos que estas están presentes únicamente en la propuesta del CNDU. La omisión de este estándar en el reglamento del gobierno es preocupante, ya que existe infraestructura y servicios de transporte público que actualmente están a capacidad máxima o presentan un hacinamiento excesivo. Por cierto, algunos recorridos de buses o Metro tienen capacidad de incrementar su frecuencia y resolver su demanda, pero otros servicios no pueden hacerlo o simplemente tienen restricciones de infraestructura que limitan un aumento de capacidad. Por ejemplo, existen distintas zonas que cumplen las condiciones de las diferentes propuestas, próximas a la Línea 1 y 4 del Metro, pero que no consideran que la Línea 1 hacia el oriente y la Línea 4 hacia el norte en punta mañana (y en sentido contrario en horario punta tarde) se encuentran a capacidades máximas y que no pueden incrementar su frecuencia de trenes, por lo que ofrecen un nivel de servicio marcado por el hacinamiento (Figura 7).
La tercera dimensión corresponde a la carga del equipamiento disponible en la zona. Este criterio está presente solamente en las propuestas del CNDU y "Ciudad con Todos”. Su ausencia en el reglamento es problemática, pues si se asume que colegios, consultorios y áreas verdes se encuentran a distancias caminables y, por lo tanto, resultan accesibles, para que esto sea efectivo es imprescindible que estas tengan capacidad para una mayor demanda.

Analicemos el caso de la propuesta de las ZBA. En ella se define una isócrona de 500 metros y un estándar de accesibilidad de 0,75 vacantes de educación por habitante. Estos criterios generan el mapa que se observa en la Figura 8. Esto deja fuera de la ecuación el hecho de que la demanda por educación puede provenir desde todos los sectores de la ciudad, donde el transporte público juega un rol clave y la competencia por esas oportunidades también. El estudio de Tiznado-Aitken et al. (2021) compara medidas potenciales (Hansen, 1959) de acceso al transporte público, es decir, considerando solo la oferta de educación y el tiempo de viaje hacia ella (Figura 8b), versus medidas competitivas (Shen, 1998) de acceso, que consideran la oferta y demanda por educación sobre un cierto estándar de calidad, además de incorporar la percepción de elementos del nivel de servicio como tiempos de espera, comodidad y número de trasbordos (Figura 8c). 
Figura 7

Carga promedio del transporte público (pasajeros de pie por metro cuadrado) en el Metro de Santiago en horario punta (7 a $9 \mathrm{am})$

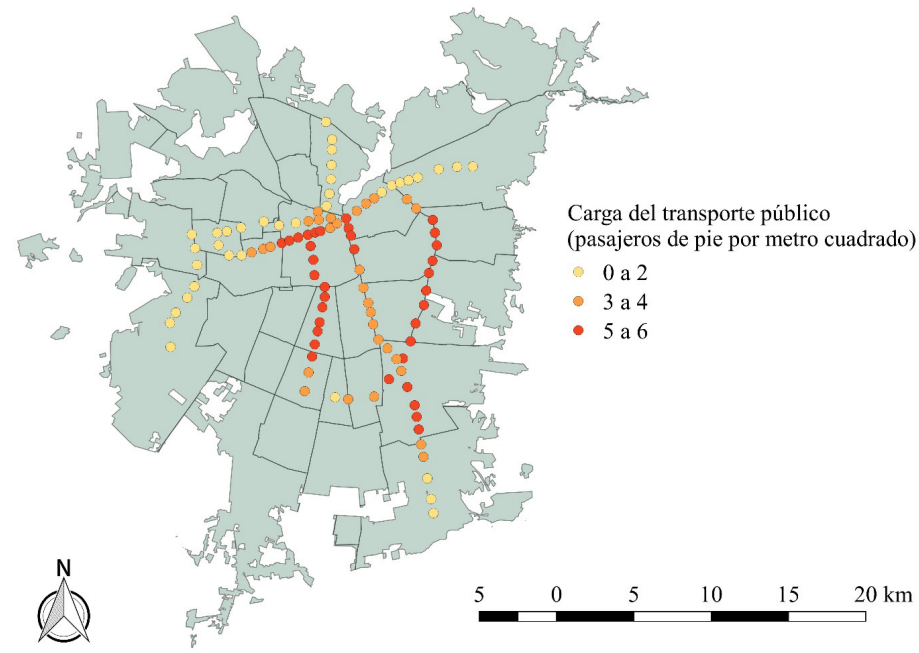

Nota: Mapa elaborado sobre la base de CEDEUS (2015) y OCUC (2020).

Figura 8

Comparación de medidas de accesibilidad educacional
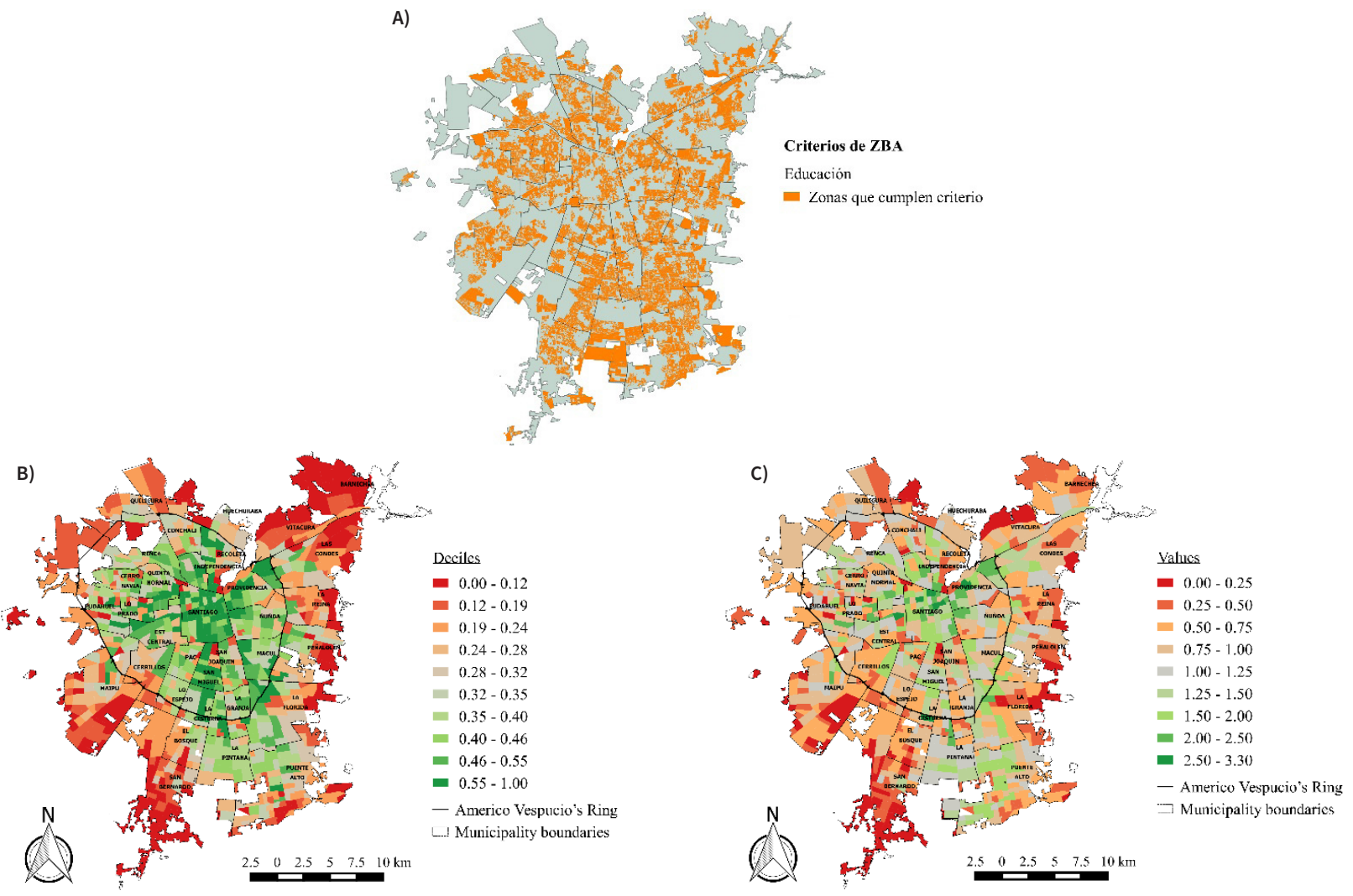

Nota: a) Arriba: zonas de Santiago que cumplen con criterio ZBA para educación. b) Abajo a la izquierda: accesibilidad a oportunidades educacionales considerando solo la oferta y los tiempos totales de desplazamiento en transporte público. c) Abajo a la derecha: accesibilidad a oportunidades educacionales considerando oferta y demanda, así como la percepción del nivel de servicio del transporte público. Mapas elaborados sobre la base de Centro de Políticas Públicas UC y Asociación de Desarrolladores Inmobiliarios (2019b) y Tiznado-Aitken et al. (2021). 
Es posible observar en las Figuras 8b y $8 \mathrm{c}$ que los patrones espaciales que se generan son diferentes y que al incluir la competencia de servicios se ofrece un panorama más cercano a la realidad que solo considerar distancias caminables y la oferta educacional. Así, la metodología utilizada por las ZBA no es la adecuada, ya que la demanda por los servicios es mayor a la que puede establecerse por un área de influencia determinada por distancia geográfica. Si bien para el criterio de áreas verdes puede que esta precisión no sea necesaria $\left(\mathrm{m}^{2}\right.$ por habitante parece ser adecuado), esto es crítico para las oportunidades de salud y educación. En esta línea, la propuesta realizada por el CNDU, considerando la capacidad ociosa actual y la demanda potencial, se aproxima de mejor manera a real demanda posdensificación en estas zonas.

\section{Discusión}

A partir del análisis anterior, se puede discutir qué elementos, umbrales o criterios se pueden incorporar para asegurar una adecuada accesibilidad al transporte público, equipamiento y una efectiva capacidad de carga en los eventuales polígonos de integración. Para ello, se presentarán cuatro subsecciones que sintetizan las tres dimensiones a discutir y nuestras propuestas en torno a tales dimensiones.

\section{Accesibilidad al transporte público}

Para aproximarse entonces a un estándar integral de accesibilidad al transporte público, se sugiere generar una serie de umbrales en distintas dimensiones. Se proponen aquí algunos de ellos:

- Accesibilidad física: en vez de utilizar distancia máxima hacia un paradero, abordando el problema de forma binaria (un paradero a 300 metros se considera accesible, pero a 301 metros es inaccesible), se propone que la accesibilidad disminuya a medida que aumenta la distancia bajo alguna forma funcional. Tiznado-Aitken et al. (2018) calibraron una función de impedancia según los tiempos reales de caminata al transporte público para 35 mil zonas de Santiago
(Figura 2). Una propuesta podría restablecer un estándar mínimo para los polígonos de integración, lo que implicaría que las personas posean un mínimo de impedancia agregada.

- Calidad del entorno caminable: son numerosas las investigaciones que muestran cómo el espacio urbano y entorno construido afecta la partición modal de transporte público (Tilahun, \& Li, 2015). Tiznado-Aitken et al. (2018) crearon un indicador de calidad urbana para caminar que integra la seguridad, medioambiente, limpieza e infraestructura, y lo aplicaron para la ciudad de Santiago (Figura 4a). En ese sentido, una propuesta podría ser establecer un mínimo de calidad del entorno caminable, con la presencia obligatoria de buenas veredas, presencia de luminaria y arbolado urbano. Esto permitiría evitar que los polígonos de integración se ubiquen en zonas donde a pesar de tener buena accesibilidad física, las condiciones de seguridad, belleza, limpieza e infraestructura afecten la accesibilidad efectiva al transporte público.

- Umbrales de tiempo de viaje: la cantidad de oportunidades que una persona puede acceder utilizando el transporte público también es una variable importante. Las medidas isócronas (Forbes, 1964) permiten conocer el número de oportunidades que son capaces de alcanzar las personas desde una zona en distintos umbrales (que pueden ser, por ejemplo, 15, 30, 45 y 60 minutos), incorporando el tiempo de acceso y de espera. A partir de la utilización de isócronas, se podría definir un umbral de tiempo de acceso a servicios o equipamiento que los polígonos de integración deben alcanzar. Por ejemplo, si es que la zona no posee atención primaria a menos de cierta distancia, entonces debo poder acceder a ella en menos de 20 minutos en transporte público (ver Tabla 3 para algunos ejemplos).

- Nivel de servicio: en la accesibilidad mediante transporte público también es central el nivel de servicio experimentado. Tiznado-Aitken et al. (2021) también crearon un indicador que incorpora el tiempo de espera, tiempo de viaje, transbordos y comodidad, donde cada componente tiene un peso diferente 
Tabla 3

Criterios de acceso a equipamiento para tres de las oportunidades urbanas esenciales

\begin{tabular}{lll}
\hline Acceso a equipamiento & $\begin{array}{l}\text { Criterio del Decreto } \mathbf{N}^{\circ} \mathbf{5 6} \\
\text { [metros] }\end{array}$ & $\begin{array}{l}\text { Posible criterio } \\
\text { [minutos caminando o utilizando transporte público] }\end{array}$ \\
\hline Educación primaria & Máx. 500 metros & Máx. 15 metros. \\
\hline Salud primaria & Máx. 1.500 metros. & Máx. 20 metros. \\
\hline \multirow{2}{*}{ Áreas verdes plazas o parques } & Plazas: Máx. 500 metros. & Máx. 10 metros. \\
\cline { 2 - 3 } & Parques: Máx. 5.000 metros. & Máx. 30 metros. \\
\hline
\end{tabular}

Tabla 4

Criterios de calidad de equipamiento para tres de las oportunidades urbanas esenciales

\begin{tabular}{|c|c|}
\hline Calidad del equipamiento & Posibles criterios \\
\hline Educación primaria & $\begin{array}{l}\text { - } \quad \text { Mínima categoría de desempeño y calidad según Agencia Nacional de la Educación. } \\
\text { - } \quad \text { Infraestructura. } \\
\text { Profesionales por número de alumnos. }\end{array}$ \\
\hline Salud & $\begin{array}{l}\text { - } \quad \text { Cantidad de profesionales. } \\
\text { - } \quad \text { Variedad de especialidades. } \\
\text { Infraestructura. }\end{array}$ \\
\hline Áreas verdes & $\begin{array}{l}\text { - } \quad \text { Metros cuadrados efectivos. } \\
\text { - } \quad \text { Mantención de áreas. } \\
\text { - }\end{array}$ \\
\hline
\end{tabular}

en la percepción generalizada del nivel de servicio del transporte público ${ }^{4}$. A partir de los orígenes y destinos de los viajes en transporte público, los autores estimaron un indicador de nivel de servicio para distintas zonas de Santiago considerando el tiempo "efectivo" y el tiempo "percibido". Una propuesta podría ser definir un nivel de servicio mínimo de transporte público, para las que ambas medidas propuestas sean útiles. De esta forma, se asegura que los polígonos de integración tengan suficiente frecuencia y no superen ciertos límites de hacinamiento y transbordos. Por último, estos indicadores podrían ser sensibles también al tipo de usuario, ya que la percepción del tiempo depende fuertemente de elementos como el género, la edad o el estrato socioeconómico (Tiznado-Aitken et al., 2020).

\section{Accesibilidad a oportunidades}

Establecer estándares de acceso y calidad razonables para los distintos equipamientos urbanos es esencial. Para esto, además de considerar la caminata a estos puntos, se debe tomar en cuenta la caminata de acceso al transporte público. Además, la calidad del equipamiento al cual se accede es relevante. Se puede pensar en utilizar información disponible sobre la calidad de colegios, la calidad de atención, profesionales y prestaciones de los centros de salud y el área, mantenimiento y continuidad de áreas verdes, entre otros. Un ejemplo de la aplicación de estos elementos a tres oportunidades esenciales dentro de la ciudad se puede encontrar en las Tablas 3 y 4 .

\section{Capacidad de carga}

Otro lineamiento que los polígonos de integración deben perseguir es considerar la capacidad de carga. Para ello, una primera aproximación consiste en impedir que estos puedan ubicarse en zonas que los instrumentos de planificación (comunales o metropolitanos) han definido como de riesgo, patrimoniales o han evitado su densificación por otras razones plausibles.

Por otra parte, se sugiere tomar en cuenta la carga en transporte público, excluyendo aquellas zonas que cargarán infraestructura que ya supera su máximo posible. Como mostramos en la Figura 7 ciertos tramos de Metro se encuentran operando a capacidad, con un nivel de hacinamiento extremo. Con base en esto, se podría asumir un estándar de hacinamiento máximo (por ejemplo,

4 Otro modelo similar es el PTAL, que incorpora la cantidad de recorridos que pasan por los paraderos y sus respectivas frecuencias para incluir elementos de tiempos de espera, coberturas y confiabilidad, estableciendo distintos niveles de accesibilidad. Shirahige y Correa (2015) lo aplicaron para Santiago según manzanas censales, por lo que podría también ser utilizado junto con algún estándar mínimo. 
Tabla 5

Propuestas de estándares de accesibilidad

\begin{tabular}{|c|c|c|}
\hline Dimensión & Elemento & Umbrales sugeridos \\
\hline $\begin{array}{l}\text { Accesibilidad a } \\
\text { transporte público }\end{array}$ & $\begin{array}{l}\text { Accesibilidad física } \\
\text { Calidad de entorno caminable } \\
\text { Tiempo de viaje } \\
\text { Nivel de servicio }\end{array}$ & $\begin{array}{l}\text { - Mínimo de impedancia agregada. Esto podría traducirse en } \\
\text { poseer un conjunto de cinco paradas de transporte público } \\
\text { dentro de } 1.000 \text { metros. } \\
\text { Presencia obligatoria de buenas veredas, presencia de } \\
\text { - } \quad \text { Oporturia y arbolado urbano. } \\
\text { transporte pública.canzadas por isócronas de } 15 \text { y } 30 \text { minutos vía } \\
\text { - Cociente máximo de dos entre tiempo percibido y tiempo real. }\end{array}$ \\
\hline \multirow{3}{*}{$\begin{array}{l}\text { Accesibilidad a } \\
\text { oportunidades }\end{array}$} & Educación primaria & $\begin{array}{l}\text { - Máximo de } 15 \text { minutos de tiempo de viaje en transporte público } \\
\text { y caminata. } \\
\text { Mínimo de categoría de desempeño y profesionales por } \\
\text { alumnos. }\end{array}$ \\
\hline & Centro de salud & $\begin{array}{l}\text { - Máximo de } 15 \text { minutos de tiempo de viaje en transporte público } \\
\text { - M caminata. } \\
\text { Mínimo de variedad de especialistas. }\end{array}$ \\
\hline & Áreas verdes & $\begin{array}{l}\text { - Máximo de 10-30 minutos de tiempo de viaje en transporte } \\
\text { público y caminata (dependiendo del tamaño). } \\
\text { - Mínimo de } 10 \mathrm{~m}^{2} \text { efectivos por habitante. }\end{array}$ \\
\hline \multirow{3}{*}{$\begin{array}{l}\text { Capacidad de } \\
\text { carga }\end{array}$} & Zonas especiales & $\begin{array}{l}\text { - } \quad \text { Exclusión de barrios patrimoniales y zonas de riesgo. } \\
\text { - Máximo de densidad bruta existente en el polígono. }\end{array}$ \\
\hline & Carga en transporte público & $\begin{array}{l}\text { Excluir de la accesibilidad a transporte público todos los } \\
\text { servicios que superen un máximo de } 4 \text { pax } / \mathrm{m}^{2} \text { en hora punta } \\
\text { mañana. }\end{array}$ \\
\hline & Carga de equipamiento & $\begin{array}{l}\text { Excluir de la accesibilidad a equipamiento todos los centros } \\
\text { o instituciones que superen un máximo de } 1,25 \text { en la relación } \\
\text { oferta/demanda por el servicio. }\end{array}$ \\
\hline
\end{tabular}

cuatro pasajeros por metro cuadrado) y considerar que estos servicios de transporte no están disponibles para estimar la accesibilidad. De forma análoga se puede evaluar el caso de recorridos de buses. Algunos podrán aumentar su frecuencia con mayor facilidad u operar bajo prioridad (pistas solo bus o corredores segregados) para cumplir con el estándar definido, pero otros no podrán asumir el aumento de densidad.

Por último, se sugiere que para analizar la carga de equipamiento se considere tanto la oferta como la demanda por servicios de acuerdo con su facilidad de accesibilidad en transporte público. Como expusimos en la Figura 8, los patrones espaciales son muy distintos al considerar estos elementos. Esto permite una estimación más realista de las oportunidades disponibles y la competencia por ellas dentro de la ciudad.

\section{Sintesis de propuestas}

A partir de lo expuesto en las tres secciones anteriores, en la Tabla 5 se muestran algunos criterios y umbrales sugeridos para mejorar la definición de las zonas que podrían recibir una mayor densificación con integración, velando por un adecuado acceso a oportunidades. En esta síntesis presentamos las tres dimensiones claves, desagregadas por cada uno de los elementos más relevantes. De esta forma, nos aseguramos de que la accesibilidad al transporte público no solo considere la proximidad física, sino que aspectos relacionados con entorno y la calidad del viaje. Por otra parte, la accesibilidad a oportunidades integra tanto transporte público como caminata, sumado a sugerencias de estándar en la calidad del equipamiento. Por último, se incorpora la capacidad de carga, excluyendo todas aquellas zonas que no sean adecuadas para recibir mayor población o proyectos de viviendas en densificación.

\section{Conclusiones}

La integración social y urbana se ha transformado en una de las prioridades de las políticas urbanas de los últimos años. Estos esfuerzos son importantes, ya que permiten mejorar las oportunidades y acceso a los bienes públicos urbanos, especialmente para los grupos más vulnerables de la población y, además, favorecen la diversidad social en el territorio. Los incentivos de normas urbanísticas son uno de los mecanismos que se han propuesto en esta línea. Estos requieren que las zonas cumplan con condiciones adecuadas de accesibilidad al transporte, al equipamiento urbano y capacidad de carga. La accesibilidad, por tanto, 
es un concepto clave para esta u otras políticas en torno a la densificación e integración social, por lo que se requiere incorporar una concepción más robusta, tanto en sí misma como en la estimación de indicadores.

Los actuales estándares de accesibilidad evaluados para el caso chileno parecen ser insuficientes o parciales. Los criterios analizados consideran la accesibilidad al transporte público y a las oportunidades urbanas como dimensiones excluyentes y solo desde la perspectiva de proximidad territorial o distancia caminable, sin tomar en cuenta las sinergias entre criterios y el rol del transporte público en la movilidad de la ciudad. Por otra parte, los criterios propuestos no consideran adecuadamente la capacidad de carga, al incluir solo áreas de influencia para determinar la demanda y obviar la capacidad de la infraestructura de transporte público, la que puede llegar a operar bajo niveles importantes de hacinamiento y asumir, por lo tanto, la presencia de una oferta inexistente.

En este trabajo, contribuimos al análisis y propuestas de algunos lineamientos que puedan ayudar a formular mejores criterios y estándares para definir los polígonos de integración social. Las dimensiones propuestas entregan un marco útil para evaluar e identificar las zonas adecuadas de densificación con integración social en cualquier país, y no solo la realidad chilena. En ese contexto, este trabajo es un aporte para comprender de mejor manera las condiciones bajo las cuales es deseable distribuir la densificación de las ciudades. Aunque los resultados y la discusión muestran que estas condiciones son más complejas de lo que parecen, esto permite que planificadores y tomadores de decisión sean conscientes de todas las posibles brechas de accesibilidad que se deben abordar.

Este trabajo se enfoca principalmente en los criterios de accesibilidad que debieran cumplir las zonas en las que es deseable densificar con integración social. Comprender la integración socioespacial exclusivamente desde la proximidad física, pasando por alto dimensiones funcionales y relacionales, podría desencadenar nuevas formas de segregación, impidiendo una verdadera distribución de recursos, poder y acceso oportunidades urbanas (RuizTagle, 2013; 2016). Dada su especificidad, nuestro trabajo posee limitaciones dado que no aborda elementos como la asequibilidad de la vivienda, la planificación urbana ni el rol de gobierno central, regional y municipal en el proyecto. Asimismo, la organización comunitaria y el impacto de la densificación en la participación y la organización de barrios consolidados no se consideran en este trabajo.

Además de los puntos expuestos anteriormente, esta investigación abre nuevos desafíos. Por una parte, se pueden evaluar los efectos de la aplicación de estas políticas en barrios donde no se cumple con las condiciones propuestas, y observar el impacto en los territorios de esta densificación. Asimismo, los avances en la literatura de accesibilidad pueden evidenciar otras dimensiones importantes a considerar, particularmente, en la relación entre accesibilidad objetiva y accesibilidad percibida. Por último, se debe tomar en cuenta la factibilidad de aplicación de los criterios propuestos en la práctica. Si bien las propuestas consideran una comprensión más integral de la accesibilidad, llevarlo a la práctica por organismos públicos o privados puede derivar en una complejidad extra. Bajo nuestro punto de vista, la capacidad técnica de los equipos de trabajo y la disponibilidad de software y datos libres son críticas para poder llevar a cabo este tipo de análisis. En casos donde estos elementos no permitan proceder, se espera que se propongan indicadores alternativos que se ajusten a la realidad de la zona de estudio, procurando considerar de forma complementaria las dimensiones de acceso a oportunidades, acceso a transporte público y capacidad de carga.

\section{Referencias bibliográficas}

Arbex, R., \& Cunha, C. B. (2020). Estimating the influence of crowding and travel time variability on accessibility to jobs in a large public transport network using smart card big data. Journal of Transport Geography, 85, 102671. https://doi.org/10.1016/j.jtrangeo.2020.102671

Bailey, N., Haworth, A., Manzi, T., Paranagamage, P., \& Roberts, M. (2006). Creating and sustaining mixed income communities: A good practice guide. Chartered Institute of Housing/Joseph Rowntree Foundation. 
Banco Interamericano de Desarrollo. (2012). Room for Development: Housing Markets in Latin America and the Caribbean. https://publications.iadb.org/en/roomdevelopment-housing-markets-latin-america-andcaribbean-summary

Bannen, P., Fuentes, L., Link, F., Ibarra, M., Matus, C., Moris, R., Orellana, A., Perrozzi A., Rojas, C., Ruiz-Tagle, J., Sabatini, F., Truffello, R. y Vicuña, M. (2019). Observaciones y propuestas al proyecto de ley de integración social y urbana (Documentos de trabajo del IEUT, $N^{\circ} 5$ ). Instituto de Estudios Urbanos y Territoriales UC.

Benenson, I., Martens, K., Rofé, Y., \& Kwartler, A. (2011). Public transport versus private car GIS-based estimation of accessibility applied to the Tel Aviv metropolitan area. The Annals of Regional Science, 47(3), 499-515. https:// doi.org/10.1007/s00168-010-0392-6

Brain, I. (2014). Incidencia Internacional de la Vivienda Inclusiva. Lincoln Institute of Land Policy.

Budds, J., \& Teixeira, P. (2005). Ensuring the right to the city: Propoorhousing, urban development and tenure legalization in Saõ Paulo, Brazil. Environment and Urbanization, 17(1), 89-113. https://doi.org/10.1177/095624780501700105

Centro de Desarrollo Urbano Sustentable. (2015). Circuitos turísticos de Chile (Datos de Sernatur). http://146.155.17.19:13080/layers/geonode:circuitos_ turisticos_2015

Centro de Políticas Públicas UC. (2016). Estudios de casos de proyectos de integración social: primer informe. Informe para Ministerio de Vivienda y Urbanismo. https://politicaspublicas.uc.cl/wp-content// uploads/2018/03/20161215-Informe-1_minvu_final.pdf

Centro de Políticas Públicas UC. (2019). Observatorio legislativo: integración social y urbana: aportes críticos para la nueva ley. https://cutt.ly/YepRTMz
Centro de Políticas Públicas UCy Asociación de Desarrolladores Inmobiliarios. (2019a). Ciudad con Todos: Diálogos para una densificación equilibrada (Reporte 1: Zonas de buena accesibilidad). https://politicaspublicas.uc.cl/ publicacion/otras-publicaciones/ciudad-con-todosreporte-n-1-zonas-de-buena-accesibilidad/

Centro de Políticas Públicas UC y Asociación de Desarrolladores Inmobiliarios. (2019b). Metodología para el cálculo de las Zonas de Buena Accesibilidad. https:// politicaspublicas.uc.cl/wp-content//uploads/2019/01/ Metodolog\%C3\%ADa-ZBA.pdf

Cheng, Y. H., \& Chen, S. Y. (2015). Perceived accessibility, mobility, and connectivity of public transportation systems. Transportation Research Part A: Policy and Practice, 77, 386-403. https://doi.org/10.1016/j. tra.2015.05.003

Chin, G. K., Van Niel, K. P., Giles-Corti, B., \& Knuiman, M. (2008). Accessibility and connectivity in physical activity studies: The impact of missing pedestrian data. Preventive Medicine, 46(1), 41-45. https://doi.org/10.1016/j. ypmed.2007.08.004

Comisión Económica para América Latina y el Caribe. (2016). The social inequality matrix in Latin America. https:// repositorio.cepal.org/handle/11362/40710

Consejo Nacional de Desarrollo Urbano (2019). Propuestas para una mayor integración social en las ciudades chilenas (Primer informe). https://cutt.ly/oepI8ow

Currie, G. (2004). Gap analysis of public transport needs: measuring spatial distribution of public transport needs and identifying gaps in the quality of public transport provision. Transportation Research Record: Journal of the Transportation Research Board, 1895(1), 137-146. https://doi.org/10.3141/1895-18 
Decreto N 56 de 2019 [Ministerio de Vivienda y Urbanismo]. Modifica Decreto Supremo $N^{\circ} 47$, de Vivienda y Urbanismo, de 1992, Ordenanza General de Urbanismo y Construcciones, con el objeto de establecer la categoría de proyectos de viviendasintegradas y regularel otorgamiento de beneficios de normas urbanísticas a dichos proyectos, conforme a los dispuesto en el DFL N² 2 , de 1959, del Ministerio de Hacienda. 10 de julio de 2019. https://www. leychile.cl/Navegar?idNorma=1133645\&buscar=20741

Delafontaine, M., Neutens, T., Schwanen, T., \& Van de Weghe, N. (2011). The impact of opening hours on the equity of individual space-time accessibility. Computers, Environment and Urban Systems, 35(4), 276-288. https:// doi.org/10.1016/j.compenvurbsys.2011.02.005

Deneulin, S., \& Sánchez-Ancochea, D. (2018). Urban inequality, youth and social policy in Latin America: introduction to special section. Oxford Development Studies, 46(1), 3-9, https://doi.org/10.1080/13600818.2017.1383375

Directorio Transporte Público Metropolitano. (2015). Tabla de viajes y estructura de tabla de viajes (Abril 2015). https:// www.dtpm.cl/index.php/documentos/matricesde-viaje

Directorio Transporte Público Metropolitano. (2019). Programas de operación. http://www.dtpm.gob.cl/index.php/ noticias/pov2

Espinoza, R. y Urzúa, S. (2018). La evolución de los precios del mercado inmobiliario: Santiago 2009-2017 (Documento de trabajo $N^{\circ}$ 52). Centro CLAPES UC. https://s3.useast-2.amazonaws.com/assets.clapesuc.cl/media post_6763_f8a86ad041.pdf

Forbes, J. (1964). Mapping accessibility. Scottish Geographical Magazine, $80(1), 12-21$.

Fransen, K., Neutens, T., Farber, S., De Maeyer, P., Deruyter, G., \&Witlox, F. (2015). Identifying public transport gaps using time-dependent accessibility levels. Journal of Transport Geography, 48, 176-187. https://doi.org/10.1016/j. jtrangeo.2015.09.008
Fraser, J. C., Oakley, D., \& Levy, D. K. (2013). Guest Editors' Introduction: Policy Assumptions and Lived Realities of Mixed-Income Housing on Both Sides of the Atlantic. Cityscape, 1-14. https://www.huduser.gov/periodicals/ cityscpe/vol15num2/guest.pdf

Gasic, I. (16 de enero de 2019). Resumen de exposición Proyecto de Ley de Integración Social Urbana. Presentación en la Comisión de Vivienda, Desarrollo Urbanoy Bienes Nacionales de la Cámara de Diputados. https://cutt.ly/pepIMiP

Hananel, R. (2014). Can centralization, decentralization and welfare go together? The case of Massachusetts Affordable Housing Policy (Ch. 40B). Urban Studies, 51(12), 2487-2502. https://doi.org/10.1177/0042098013512877

Handy, S. (2020). Is accessibility an idea whose time has finally come? Transportation Research Part D: Transport and Environment, 83, 102319. https://doi.org/10.1016/j. trd.2020.102319

Hansen, W. G. (1959). How Accessibility Shapes Land Use. Journal of the American Institute of planners, 25(2), 73-76. https://doi.org/10.1080/01944365908978307

Hernandez, D. (2018). Uneven mobilities, uneven opportunities: Social distribution of public transport accessibility to jobs and education in Montevideo. Journal of Transport Geography, 67, 119-125. https://doi.org/10.1016/j. jtrangeo.2017.08.017

Iacono, M., Krizek, K. J., \& El-Geneidy, A. (2010). Measuring non-motorized accessibility: issues, alternatives, and execution. Journal of Transport Geography, 18(1), 133140. https://doi.org/10.1016/j.jtrangeo.2009.02.002

IDE Observatorio Ciudades UC. (2019). Estado áreas verdes de Santiago. https://ideocuc-ocuc.hub.arcgis.com/ datasets/1ae5e0b957124176844f48b935fa8d2f_0

IDE Observatorio de Ciudades UC. (2020). Equipamiento cultural de la Región Metropolitana. https://ideocuc-ocuc.hub.arcgis. com/datasets/d8c16ab7eee04de892de5696d40c94f7_0 
Iglesias, V., Giraldez, F., Tiznado-Aitken, I., \& Muñoz, J.C. (2019). How uneven is the playing field? An analysis of transportrelated inequalities among socioeconomic groups in Santiago, Chile. Transportation Research Record, 2673(11), 59-70. https://doi.org/10.1177/0361198119849588

Instituto Nacional de Estadística. (2011). Precenso Nacional. (Documento inédito).

Kawabata, M. (2009). Spatiotemporal dimensions of modal accessibility disparity in Boston and San Francisco. Environment and Planning A, 41(1), 183-198. https:// doi.org/10.1068/a4068

Lei, T. L., \& Church, R. L. (2010). Mapping transit-based access: integrating GIS, routes and schedules. International Journal of Geographical Information Science, 24(2), 283-304. https://doi.org/10.1080/13658810902835404

Lelévrier, C. (2013). Social mix neighbourhood policies and social interaction: The experience of newcomers in three new renewal developments in France. Cities, 35, 409-416. https://doi.org/10.1016/j.cities.2013.03.003

Ley $\mathrm{N}^{\circ} 20.741$ de 2014. Modifica la ley $\mathrm{N}^{\circ} 19.537$, sobre copropiedad inmobiliaria, para facilitar la administración de copropiedades y la presentación de proyectos de mejoramiento o ampliación de condominios de viviendas sociales. 25 de marzo de 2014. D.O N40.821

Lovett, A., Haynes, R., Sünnenberg, G., \& Gale, S. (2002). Car travel time and accessibility by bus to general practitioner services: a study using patient registers and GIS. Social Science \& Medicine, 55(1), 97-111. https://doi.org/10.1016/ s0277-9536(01)00212-X

Lucas, K. (2012). Transport and social exclusion: Where are we now? Transport Policy, 20, 105-113. https://doi. org/10.1016/j.tranpol.2012.01.013

Lucas, K., Mattioli, G., Verlinghieri, E., \& Guzman, A. (2016). Transport poverty and its adverse social consequences. Proceedings of the Institution of Civil Engineers-Transport, 169(6), 353-365. https://doi.org/10.1680/jtran.15.00073
Mamun, S. A., Lownes, N. E., Osleeb, J. P., \& Bertolaccini, K. (2013). A method to define public transit opportunity space. Journal of Transport Geography, 28, 144-154. https://doi.org/10.1016/j.jtrangeo.2012.12.007

Martens, K. (2017). Transport justice: Designing fair transportation systems. Routledge.

Mavoa, S., Witten, K., McCreanor, T., \& O'sullivan, D. (2012). GIS based destination accessibility via public transit and walking in Auckland, New Zealand. Journal of Transport Geography, 20(1), 15-22. https://doi.org/10.1016/j. jtrangeo.2011.10.001

Merlin, L. A., \& Hu, L. (2017). Does competition matter in measures of job accessibility? Explaining employment in Los Angeles. Journal of Transport Geography, 64, 77-88. https://doi.org/10.1016/j.jtrangeo.2017.08.009

Ministerio de Educación. (2016). Portal de datos abiertos. Centro de Estudios Mineduc. https://datosabiertos. mineduc.cl/

Ministerio de Educación. (2017). Descripción general del SNED. https://www.ayudamineduc.cl/ficha/descripciongeneral-sned

Molina, I. (1986). El Programa de erradicación de campamentos en la Región Metropolitana de Santiago (1979-1984): implicancias socioeconómicas y espaciales [Tesis de grado] Pontificia Universidad Católica de Chile, Santiago, Chile.

Morales, E. y Rojas, S. (1987). Relocalización socio espacial de la pobreza. Política estatal y presión popular. En J. Chateau, B. Gallardo, E. Morales, C. Piña, H. Pozo, S. Rojas, D. Sánchez y T. Valdés (Eds.), Espacio y poder: los pobladores (pp. 75-120). Flacso.

Moreno-Monroy, A. I., Lovelace, R., \& Ramos, F. R. (2018). Public transport and school location impacts on educational inequalities: Insights from São Paulo. Journal of transport geography, 67, 110-118. https://doi.org/10.1016/j. jtrangeo.2017.08.012 
Neutens, T., Delafontaine, M., Scott, D. M., \& De Maeyer, P. (2012). An analysis of day-to-day variations in individual space-time accessibility. Journal of Transport Geography, 23, 81-91.https://doi.org/10.1016/j.jtrangeo.2012.04.001

Pereira, R. H., Schwanen, T., \& Banister, D. (2017). Distributive justice and equity in transportation. Transport Reviews, 37(2), 170-191. https://doi.org/10.1080/01441647.2016.1257660

Polzin, S. E., Pendyala, R. M., \& Navari, S. (2002). Development of Time-of-Day-Based Transit Accessibility Analysis Tool. Transportation Research Record, 1799(1), 35-41. https:// doi.org/10.3141/1799-05

Programa de las Naciones Unidas para el Desarrollo. (2016). Desiguales: orígenes, cambiosy desafíos de la brecha social en Chile. Edición del autor. https://www.cl.undp.org/content/ chile/es/home/library/poverty/desiguales--origenescambios-y-desafios-de-la-brecha-social-en-html

Razmilic, S. y Larraín, C. (2019). Notas sobre el proyecto de ley de integración socialy yurbana.Punto de Referencia, (523). https:// www.cepchile.cl/cep/site/docs/20191216/20191216154310/ pder523_clarrain_srazmilic.pdf

Rossetti, T., Lobel, H., Rocco, V., \& Hurtubia, R. (2019). Explaining subjective perceptions of public spaces as a function of the built environment: A massive data approach. Landscape and Urban Planning, 181, 169-178. https:// www.researchgate.net/publication/333488805_ Explaining_subjective_perceptions_of_public_spaces_ as_a_function_of_the_built_environment_A_massive_ data_approach

Ruiz-Tagle, J. (2013). A theory of Socio-spatial integration: Problems, Policies and Concepts from a US Perspective. International Journal of Urban and Regional Research, 37(2), 388-408. https://doi.org/10.1111/j.14682427.2012.01180.x

Ruiz-Tagle, J. (2016). The broken promises of social mix: the case of the Cabrini Green/Near North area in Chicago. Urban Geography, 37(3), 352-372. https://doi.org/10.1 080/02723638.2015.1060697
Ryus, P., Ausman, J., Teaf, D., Cooper, M., \& Knoblauch, M. (2000). Development of Florida's Transit Level-of-Service Indicator. Transportation Research Record, 1731(1), 123-129. https://doi.org/10.3141/1731-15

Sarmiento, O. L., Schmid, T. L., Parra, D. C., Díaz-del-Castillo, A., Gómez, L. F., Pratt, M., Jacoby, E. Pinzón, J. D. \& Duperly, J. (2010). Quality of life, physical activity, and built environment characteristics among colombian adults. Journal of Physical Activity and Health, 7(2), 181-195. https://doi.org/10.1123/jpah.7.s2.s181

Shen, Q. (1998). Location characteristics of inner-city neighborhoods and employment accessibility of lowwage workers. Environment and planning B: Planning and Design, 25(3), 345-365. https://doi.org/10.1068/ b250345

Shirahige, M. y Correa, J. (2015). La desigualdad en el acceso al transporte público en el área metropolitana de Santiago: Análisis mediante la aplicación del modelo PTAL en campamentos y villas de blocks. Revista CIS, 12(18), 55-89. https://dialnet.unirioja.es/servlet/ articulo? codigo $=6310256$

Tapia, R. (2011). Vivienda social en Santiago de Chile. Análisis de su comportamiento locacional, período 1980- 2002. Revista INVI, 26(73), 105-131. https://doi. org/10.4067/s0718-83582011000300004

Tilahun, N., \& Li, M. (2015). Walking access to transit stations: evaluating barriers with stated preference. Transportation Research Record, 2534(1), 16-23. https://doi. org/10.3141/2534-03

Tiznado-Aitken, I., Hurtubia, R. \& Muñoz, J.C. (2017). How equitable is access to opportunities and basic services considering the impact of the level of service? The case of Santiago, Chile (International Transport Forum Discussion Papers, N²016/15). OECD Publishing. https://doi.org/10.1787/2223439X 
Tiznado-Aitken, I., Lucas, K., Muñoz, J.C. \& Hurtubia, R. (2020). Understanding accessibility through public transport users' experiences: A mixed methods approach. Journal of Transport Geography, 88. https://doi.org/10.1016/j. jtrangeo.2020.102857

Tiznado-Aitken, I., Muñoz, J. C., \& Hurtubia, R. (2018). The Role of Accessibility to Public Transport and Quality of Walking Environment on Urban Equity: The Case of Santiago de Chile. Transportation Research Record, 2672(35), 129-138. https://doi.org/10.1177/0361198118782036

Tiznado-Aitken, I., Muñoz, J.C., \& Hurtubia, R. (2021). Public transport accessibility accounting for level of service and competition for urban opportunities: an equity analysis for education in Santiago de Chile. Journal of Transport Geography, 90. https://doi.org/10.1016/j. jtrangeo.2020.102919

Vale, D. S., Saraiva, M., \& Pereira, M. (2015). Active accessibility: A review of operational measures of walking and cycling accessibility. Journal of Transport and Land Use, 9(1). https://doi.org/10.5198/jtlu.2015.593

Vecchio, G., Tiznado-Aitken, I., \& Hurtubia, R. (2020). Transport and equity in Latin America: a critical review of socially oriented accessibility assessments. Transport Reviews, 40(3), 354-381. https://doi.org/10.1080/01441647.202 0.1711828

Weber, J., \& Kwan, M. P. (2002). Bringing time back in: A study on the influence of travel time variations and facility opening hours on individual accessibility. The Professional Geographer, 54(2), 226-240. https://doi. org/10.1111/0033-0124.00328

Wu, B. M., \& Hine, J. P. (2003). A PTAL approach to measuring changes in bus service accessibility. Transport Policy, 10(4), 307-320. https://doi.org/10.1016/s0967-070x(03)00053-2 